\title{
Implementasi Penggunaan Smartphone Android untuk Control PC (Personal Computer)
}

\author{
Imam Solikin*) \\ Jurusan Manajemen Informatika, Fakultas Vokasi, Universitas Binadarma Palembang \\ Jln. A. Yani, Seberang Ulu I, Kota Palembang 30264, Indonesia \\ email: imamsolikin@binadarma.ac.id
}

Received: 7 Februari 2018; Revised:14 Mei 2018; Accepted: 14 Mei 2018

Copyright @2018 Politeknik Harapan Bersama Tegal. All rights reserved

\begin{abstract}
The purpose of this research is to simplify the control of personal computer (PC) such as control pointer, keyboard control and make it easier to do the presentation by controlling the slide remotely using smartphone through wifi connections facility. The smartphone is a multimedia phone that combines PC functionality with microprocessor, memory, and built-in modem to produce smart smartphone gadgets. Problems that occur when performing a presentation such as PC control, control pointer and keyboard control for input should be close to the PC so it is less than optimal in explaining the material. The model used in implementing the use of Android Smartphone for PC control is a conceptual model consisting of several stages: potential and problems, data collection, system testing, test results, and system implementation or implementation. From the results of $\mathrm{PC}$ control research can be done by connecting the Smartphone with a PC via wifi network so that $P C$ can be controlled remotely. PC control application is an application that can control PC remotely connected via wifi network connection. Benefits derived from this research make it easy to mengedalikan PC remotely such as facilitate in the percentage and control pointer and control Keyboard for input process.
\end{abstract}

Abstrak - Tujuan dilakukannya penelitian ini untuk mempermudah control personal computer (PC) seperti control pointer, control keyboard dan mempermudah melakukan persentasi dengan meng-control slide dari jarak jauh menggunakan smarphone melalui fasilitas connetions wifi. Smartphone merupakan ponsel multimedia yang menggabungkan fungsionalitas PC dengan mokroprosesor, memori, dan modem bawaan sehingga menghasilkan gadget smartphone pintar. Permasalahan yang terjadi ketika melakukan persentasi seperti saat mengontrol PC, control pointer dan control keyboard untuk penginputan harus berada dekat dengan PC sehingga kurang optimal dalam memberi penjelasan materi. Model yang digunakan dalam implementasi penggunaan Smartphone Android untuk control PC adalah model konseptual yang terdiri dari beberapa tahap yaitu potensi dan masalah, pengumpulan data, uji coba sistem, hasil uji coba, dan penerapan atau implementasi sistem. Dari hasil penelitian control PC dapat dilakukan dengan cara mengkoneksikan Smartphone dengan PC melalui jaringan wifi sehingga PC bisa di-control dari jarak jauh. Aplikasi control PC merupakan aplikasi yang dapat control PC dari jarak jauh yang dihubungkan melalui koneksi jaringan wifi. Manfaat yang didapat dari penelitian ini memberi kemudahan untuk mengendalikan PC dari jarak jauh seperti mempermudah

\footnotetext{
*) Corresponding author: Imam Solikin

Email: imamsolikin@binadarma.ac.id
}

dalam melakukan persentasi dan control pointer dan control Keyboard untuk proses penginputan.

Kata Kunci - Smartphone, android, control PC

\section{PENDAHULUAN}

Perkembangan teknologi smartphone di Negara Indonesia mengalami perkembangan sangat pesat. Smartphone merupakan telephone selular dengan mikroprosesor, memory, screen dan modem bawaan [1]. Smartphone merupakan telephone yang memiliki fitur-fitur dengan kemanpuan melebihi telephone pada umumnya, hal ini bias dilihat dengan keberadaan fitur tambahan selain untuk komunikasi, seperti fasilitas pendukung tambahan aplikasi. Kemajuan teknologi dan informasi dapat dilihat dengan semakin banyaknya pengunaan smartphone sebagai Alat Bantu yang mutakhir, yang bertujuan untuk mempermudah pekerjaan manusia, sehingga waktu yang digunakan semakin cepat, dan mudah [2]. Adapun beberapa jenis operating system (OS) yang dijalankan pada smartphone yaitu iPhone operating system, Android operating system, BlackBerry operating system dan sebagainya. Itu merupakan sebagian dari Operating System yang dijalankan oleh vendor-vendor dan perusahaanperusahaan besar di dunia [3].

Adapun salah satu aplikasi yang telah dikembangkan yaitu aplikasi connetions wifi. Aplikasi ini berfungsi untuk control personal computer (PC) seperti control pointer, control keyboard, dan control slide media persentasi. Pemasalah yang muncul sebelum menggunakan aplikasi ini ketika melakukan persentasi ketika pengontrolan PC, pengontrolan pointer dan pengontrolan keyboard pengguna harus dekat dan langsung mengoprasikan PC, sehingga kurang optimal dalam melakukan persentasi. Berdasarkan permasalahan tersebut peneliti mencari cara untuk control PC dari jarak jauh dalam proses pengendalian pointer, keyboard dan media persentasi.

Negara Indonesia merupakan digital technology giant di Asia yang sedang tertidur. Jumlah penduduk di Negara Indonesia mancapai 250.000.000 jiwa merupakan pasar yang besar. Pengguna smartphone di Negara Indonesia mengalami pertubuhan sangat pesat. Lembaga riset digital marketing Emarketer memperkirakan pada tahun 2018 jumlah pengguna aktif smartphone di Negara Indonesia lebih dari 100.000.000 jiwa. Dengan jumlah sebesar itu, Negara Indonesia akan menjadi negara dengan pengguna aktif smartphone terbesar keempat di dunia setelah Cina, India, dan Amerika [4]. 
Smarthone Android pertama mulai dipasarkan pada bulan Oktober 2008 [5]. Selain itu platform open source Android memberikan kebebasan kepada pengembang untuk berkontribusi pada pertumbuhan yang pesat dari pasar Android. Android merupakan operating system yang paling popular untuk smartphone dibandingkan sistem operasi lain. Smartphone android menyediakan platform terbuka bagi para developers dalam menciptakan aplikasi mereka sendiri untuk digunakan oleh bermacam peranti bergerak [6]

Teknologi Smartphone dapat dijadikan salah satu solusi untuk control PC dari jarak jauh. Sekarang ini smartphone tidak hanya berfungsi sebagai sarana telekomunikasi, namun juga telah beralih menjadi gadget yang mampu melakukan banyak hal. Pada penelitian peneliti. Penggunaan teknologi smartphone tersebut dapat diterapkan dalam penggunaan aplikasi connetions wifi. Tujuan dari penelitian untuk mempermudah control PC dari jarak jauh menggunakan connetions wifi. Hotspot (Wi-Fi) merupakan salah satu standar Wireless Netwoking nir-kabel, hanya dengan komponen yang sesuai dapat terkoneksi ke jaringan [7]. Dengan adanya sistem control mempermudah mengendalikan personal computer dari jarak jauh seperti pengendalian pointer, mengendalian keyboard, mempermudah dalam melakukan persentasi dengan pengendalian slide dari jarak jauh dan lain-lain.

\section{PENELITIAN YANG TERKAIT}

Desain interaksi aplikasi pengendali smart home menggunakan Smartphone Android [8]. Perancangan pengendali rumah menggunakan smartphone android dengan konektivitas bluetooth [9]. Pengendalian pintu pagar geser menggunakan aplikasi smartphone android dan mikrokontroler arduino melalui bluetooth [10]. Artikel ini digunakan untuk mempertegas penggunaan smartphone dalam control perangkat seperti pengendalian smart home, perancangan rumah, dan pengendalian pintu pagar.

Implementasi VPN untuk akses server melalui perangkat mobile pada jaringan komputer SMK Triatma Jaya Semarang [11]. Implementasi smart identification menggunakan perangkat smartphone dengan raspberry PI (studi kasus: SMAN 2 Balikpapan [11]. Artikel penelitian ini menguatkan kajian pengimplementasian penggunaan Smartphone. Implementasi remote desktop komputer menggunakan Virtual Network Computing (VNC) Server dan VNC Viewer berbasis android [13]. Implementasi accelerometer pada smartphone android sebagai media player controller pada PC [14]. Artikel penelitian ini menguatkan kajian teknis.

\section{METODE PENELITIAN}

Metode penelitian merupakan cara ilmiah untuk mendapatkan data dengan tujuan dan kegunaan tertentu [15].

\section{A. Teknik Pengumpulan Data}

Pengumpulan data merupakan komponen yang penting dalam penelitian. Teknik dokumentasi merupakan catatan peristiwa yang sudah berlalu. Studi dokumen merupakan pelengkap dari penggunaan metode observasi dan metode wawancara dalam penelitian kualitatif [15]. Observasi dilakukan ketika menggunakan menggunakan control PC. Wawancara dilakukan kepada pengguna smartphone yang akan menngunakan connetions wifi.

\section{B. Kerangka Berpikir}

Kerangka berfikir merupakan model konseptual tentang bagaimana teori berhubungan dengan berbagai faktor yang telah diidentifikasi sebagai masalah yang penting [15].

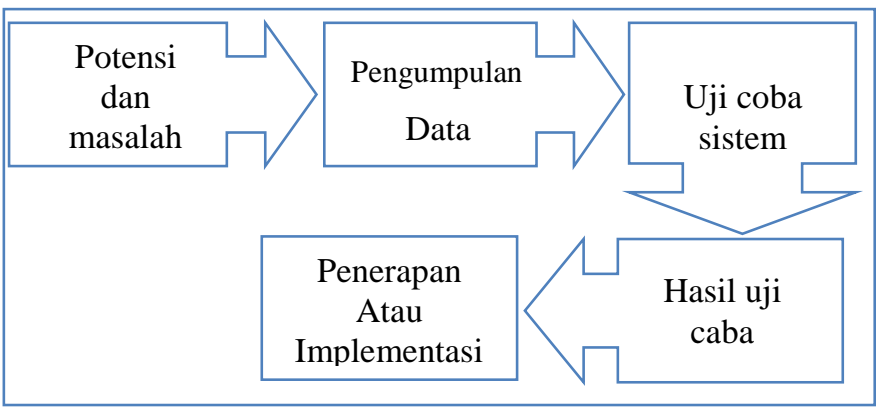

Gbr. 1 Kerangka berfikir.

Berdasarkan kerangka berfikir yang diperlihatkan pada Gbr.1, maka dalam penelitian ini untuk mengimplementasikan aplikasi connetions wifi dengan langkah-langkah pengerjaan sesuai dengan kerangka berfikir, sebagai berikut:

a) Potensi dan masalah: potensi yang didapat teknologi smartphone yaitu perkembangan perangakat kerat dan perangakat lunak. Perkembangan teknologi smartphone di Indonesia sangatlah cepat sehingga bisa digunakan untuk media control PC melalui smartphone. Masalah yang dihadapi kurang pengetahuan dalam memanfaatkan teknologi smartphone.

b) Pengumpulan data: pengumpulan data dilakukan melalui interview dan observasi. Interview dilakukan kepada dosen yang menggunakan smartphone, PC dan dosen yang melakukan presentasi dalam proses mengajar. Observasi dilakukan terhadap smartphone dan PC yang digunakan.

c) Uji coba sistem: memastikan mutu dari aplikasi connetions wifi apakah aplikasi yang diimplementasikan sesuai dengan kebutuhan. Pengujian juga merupakan analisa aplikasi connetions wifi yang bertujuan untuk melihat kondisi yang dinginkan.

d) Hasil uji coba: dari uji coba meproleh suatu hasil yang berupa aplikasi yang digunakan untuk control PC menggunakan connetions wifi, dalam hasil ini syarat dan kegunaan sudah terpenuhi

e) Penerapan atau implementasi:, merupakan tahap dimana suatu aplikasi connetions wifi digunakan.

\section{HASIL DAN PEMBAHASAN}

Penelitian ini memperoleh hasil berupa pengimplementasian penggunaan smartphone (sistem operasi android) untuk control PC. Control PC dapat dilakukan dengan cara mengkoneksikan melalui media layanan wifi sehingga PC dapat dikendalikan dari jarak jauh seperti pengendalian pointer, pengendalian keyboard dan dapat dimaafaatkan untuk mempermuda persentasi dalam mengendalikan Slide. Proses koneksi dapat dilakukan dengan menghidupkan layanan hostpot pada smartphone kemudian pada PC menghubungkan wireless dengan wifi. Koneksi hostpot akan terhubung ke PC dengan mengenali ip address smarphone. 
A. Proses Conneting Smartphone dan PC

Pada proses ini sangat penting karena sebelum pelakukan control smartphone terhadap PC, maka harus ter-conneksi terlebih dahulu antara smartphone dengan PC. Proses conneting dapat di libat pada Gbr 2. Dalam proses ini smartphone harus menghidupkan fasilitas mobile hotspot dan PC mencari name hostpot dari smartphone.

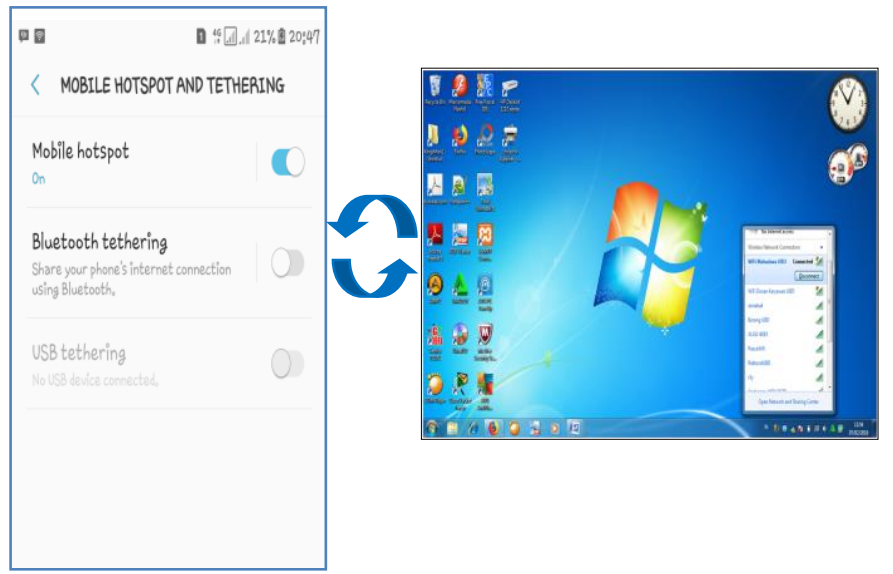

Gbr. 2 conneting wifi smartphone dengan personal computer.



Gbr. 3 conneting control smartphone dengan personal computer

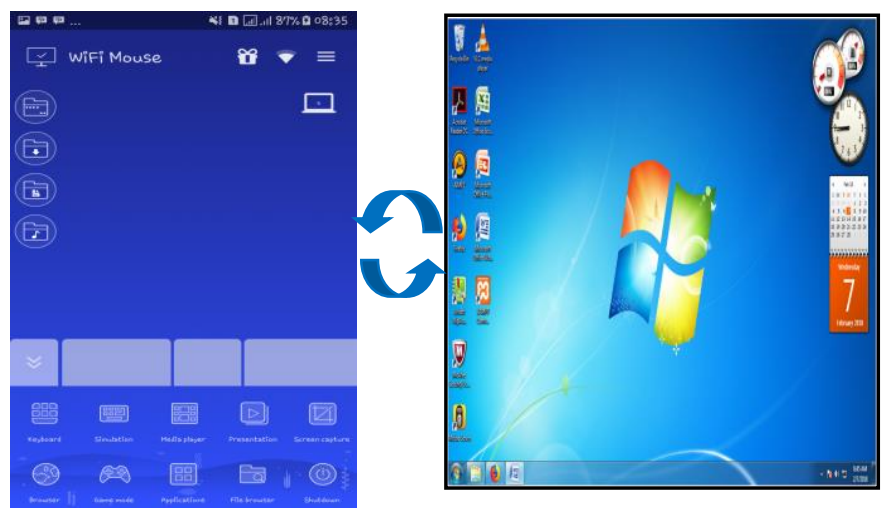

Gbr. 4 hasil conneting control smartphone dengan personal computer

\section{B. Connecting Control Smartphone dengan PC}

Pada proses Gbr.3, PC akan terhubung dengan mengenali ip address smartphone, sehingga smartphone bisa mengontrol PC (mengontrol pointer, keyboard, bahkan mengontrol media slide persentasi).

\section{Menggunakan Control Smartphone dengan PC}

Pada proses ini antara smartphone dengan PC sudah terhubung dan bisa melakukan control. Control yang dapat dilakukan Seperti pengendalian pointer, pengedaliaan fungsi keyboard dan bisa digunakan untuk pengendalian slide ketika melakukan presentasi.

\section{KESIMPULAN}

Kesimpulan yang diperoleh dari penelitian ini yaitu memberikan manfaat dalam penggunaan smartphone dan PC dalam control PC menggunakan aplikasi connetions wifi sebagai control PC dan layanan wifi untuk menghubungkan perangkat smartphone dan PC. Aplikasi ini menjadi solusi untuk control PC dari jarak jauh. Secara teknik control PC ini tidak perlu menggunakan jaringan internet hanya mengghubungkan antara smartphone dengan PC.

Implementasi dari penelitian ini adalah pemanfaatan smartphone untuk control PC seperti control pointer, control keyboard, bahkan control slide media persentasi. Untuk hasil yang lebih baik lagi perlu adanya pengujian yang lebih dengan jarang uji lebih jauh lagi misalnya 50 - 100 meter. Saran peneliti agar bisa dilanjutkan dengan ketentuan jarak lebih jauh lagi dengan cara memper luar radius hostpot dan wifi pada perangkat smartphone dan PC.

\section{UCAPAN TERIMA KASIH}

Peneliti mengucapan terima kasih kepada pengurus jurnal pengembangan IT yang telah memberikan fasilitas untuk mempublikasi artikel penelitian ini.

\section{DAFTAR PUSTAKA}

[1] B. K. Williams dan S. C. Sawyer, Using Information Technology: A Practical Introduction to Computers \& Communications, New York: McGraw-Hill, 2011.

[2] T. Deify, "Manfaat Penggunaan Smartphone Sebagai Media Kemunikasi," Acta Diurna, vol. 02.

[3] A. Satyaputra, Beginning Android Programming, Jakarta: Kompas Gramedia, 2014.

[4] [Online]. Available: https://www.kominfo.go.id/content/detail/6095/indonesia-raksasateknologi-digital-asia/0/sorotan_media. [Diakses 75 2018].

[5] Y. Murya, Pemrograman Android, Jakarta: Jasakom, 2014

[6] S. H. Nazarudin, Pemograman Aplikasi Mobile Smartphone dan Tablet PC Berbasis Android, Badung: Informatika, 2012.

[7] T. P. Kuntoro, Jaringan WI-FI, Yogyakarta: Andi, 2015.

[8] A. D. B. Sadewo, E. R. Widasari dan A. Muttaqin, "Perancangan Pengendali Rumah menggunakan Smartphone Android dengan Komektivitas Bluetooth," J-PTIIK (Jurnal Pengembangan Teknologi Informatika dan Ilmu Komputer), vol. 1, no. 2, pp. 415-425, Mei 2017.

[9] T. O. Mayasari, E. R. Widasari dan H. Fitriyah, "Desain Interaksi Aplikasi Pengendali Smart Home Menggunakan Smartphone Android," J-PTIIK (Jurnal Pengembangan Teknologi Informatika dan Ilmu Komputer), vol. 1, no. 2, pp. 139 - 147, Februari 2017

[10] A. Syofian, "Pengendalian Pintu Pagar geser menggunakan Aplikasi 
Smartphone Android dan Mikrokontroler Arduino Melalui Bluetooth,' JTE-ITP (Jurnal Teknik Elektro ITP), vol. 5, no. 1, pp. 45-50, Januari 2015.

[11] P. A. Bagyono dan F. A. Sutanto, "Implementasi VPN untuk Akses Server Melalui Perangkat Mabile pada Jaringan Komputer SMK Triatma Jaya Semarang," dalam SENDI-U (Seminar Nasional Multi Disipli Ilmu \& Call For Papers Unisbank), Semarang, 2017.

[12] A. Alfarizi, R. Primananda dan R. A. Siregar, "Implementasi Smart Indentification menggunakan Perangkat Smartphone dengan Raspberry PI (Studi Kasus : SMAN 2 Balikpapan)," J-PTIIK (Jurnal Pengembangan Teknologi Informasi dan Ilmu Komputer), vol. 2, no. 2, pp. 2899 - 2906, Agustus 2018
[13] Y. Ariyanto, “. Implementasi Remote Desktop Komputer Komputer Menggunakan Virtual Network Computing (VNC) Server dan VNC Viewer Berbasis Android," dalam SENTIA, Malang, 2015.

[14] R. Yunasa, M. R. Rumani dan R. E. Saputra, "Implementasi Accelerometer pada Smartphone Android sebagai Media Player Controller pada PC," dalam e-Proceeding of Engneering, 2015.

[15] Sugiyono, Metode Penelitian Pendidikan Pendekatan Kuatitatif, Kualitatif dan R \& D, Bandung: Alfabeta, 2013. 